\title{
An Investigation into the Systematic Meaning of Sensuous-Certainty in Hegel
}

\author{
Timothy Schatz
}

The quintessential characterization of Hegel's philosophy is that of a circle. In the context of his Phenomenology of Spirit, this means a kind of unity or semblance thereof between sensuous-certainty and absolute knowing. In this paper, I demonstrate the aforementioned unity through a reading of the section on sensuouscertainty, one which is mediated by the work of Jean Hyppolite and Jay Bernstein. Through this approach, I highlight several issues of metaphysical importance, viz., space, time, object, and subject, at the beginning of Hegel's text, as well as delineating an underlying ethical matter of responsibility vis-à-vis the capacity to remember.

\section{A Brief Outline of the Investigation}

The aim of this investigation is to answer what it means for sensuous-certainty to be the beginning of Hegel's Phenomenology of Spirit. At the outset of my investigation, I have two presumed conceptions that inform my reading, that of Jean Hyppolite and Jay Bernstein. This paper will thereby take the two conceptions together in order to unify the beginning and end of the Phenomenology. The result is what I term the "spatiotemporal subject-object ensemble," i.e., the self, the object, the now, and the here. The conceptualization of this representation is the meaning of absolute knowing, which, through investigating, will enable us to understand sensuous-certainty. From the vantage point of the end, for us it stands that sensuous-certainty is essentially a disavowal of mediation, which, in the affirmation of mediation in its sublation, ${ }^{1}$ results in a drawing forth of the said ensemble and necessarily holding onto it in memory and taking responsibility for this activity.

\section{Initial Considerations: Bernstein and Hyppolite}

Hyppolite's conception of sensuous-certainty in his book, Genesis and Structure of Hegel's

1. This term presents a number of issues in English, made worse by certain translations, and by the fact that Phenomenology of Spirit is essentially a first draft. Though we are no strangers to homonymy, we often are taken aback by the idea that the word has three different meanings: lifting up, preserving, and negating. In German, Aufhebung retains these three uses. However, as Hegel discusses in his Encyclopedia, he only means two of these: preserving and negation. Hegel's insight is that negation has a preservative effect, and any inclination of upward movement is something forced onto Hegel by readers. The image of Hegelian philosophy is said to be a circle, and the sublation of a contradiction is realizing the limits of that circle within a sphere. The movement is therefore not about subsuming everything but in unifying the world in its differences, from organically moving through thought determinations in an enriching process. The key to this paper here is in this fact, i.e., that we do not leave things behind but realize how they stay with us (i.e., are preserved) and return in new contexts. 
Phenomenology of Spirit, is twofold. First, he presents it in regard to absolute knowing and, in the second, to the prior sections in the Philosophy of Spirit. In regard to the first he says: "If we are to grasp the whole of Hegel's thought, we must understand this starting point of his philosophy: the intuition of life or of the I which develops by opposing itself and rediscovering itself." $2 \mathrm{He}$ continues, "Hegel shows how consciousness begins with equality that will later be its end, the goal that it will strive to reach, to reconquer reflectively ... In the first chapter, truth and certainty are immediately equal; in the last chapter certainty, i.e., subjectivity, has posed itself in being, posed itself as truth, and truth, i.e., objectivity, has shown itself to be certainty, self-consciousness."3 Hyppolite locates the notion of this unity of truth and certainty as a result of the sublation of the sensuous soul of anthropology. ${ }^{4}$ This sublation represents a "moment of separation" between the subject and object. ${ }^{5}$ Hyppolite thereby presents his conception of sensuous-certainty as the break with the nondistinguishing perspective of the sensuous soul: "The soul no longer senses but is consciousness: it has a sensuous intuition. This distinction is present in its simplest form at the beginning of the Phenomenology."6

Bernstein's conception proves fruitful in combination with Hyppolite's, i.e., in relation to the break with the sensuous soul. Bernstein, in his published audio lectures, says:

So rather than think of immediacy as immediate-that's the wrong view-I'm suggesting that immediacy is itself an expression of a desire to escape from conditionedness, mediation. It wants to escape from the burden that we have to tell the difference between true and false. And that, indeed, in knowledge we are responsible in some way for truth-telling and, therefore, distinguishing truth from false. $^{7}$

Such a position expresses Hegel's overarching suspicion of forms of immediate knowing. In his Encyclopedia, Hegel notes the need to overcome immediate knowing in order to engage in science. ${ }^{8}$ Further, Hegel adds in the preface of his Phenomenology that immediate knowing is devoid of spirit,

2. Jean Hyppolite, Genesis and Structure of Hegel's Phenomenology of Spirit, trans. Samuel Cherniak and John Heckman, (Evanston: Northwestern University Press, 1979), 81.

3. Hyppolite, Genesis and Structure, 81-82.

4. The third volume of Hegel's Encyclopedia concerns spirit and in many ways re-systematizes his Phenomenology of Spirit. Hyppolite's reading thereby situates itself in the context of the later system.

5. Hyppolite, Genesis and Structure, 84.

6. Hyppolite, Genesis and Structure, 84.

7. Jay M. Bernstein, "Phenomenology of Spirit Lectures 1 to 30," Lecture 1, Part 1, 06:59-07:41, https:// bernsteintapes.com/hegellist.html.

8. G.W.F. Hegel, Encyclopedia of the Pbilosophical Sciences in Basic Outline, Part I: Science of Logic, trans. and eds. Klaus Brinkmann, and Daniel O. Dahlstrom, (Cambridge: Cambridge University Press, 2015), \$78. Hereafter cited as EL. 
which is called sensuous consciousness. ${ }^{9}$ It appears that the younger Hegel held the opposite view, but, as Brady Bowman discusses, he later turned against the idea of a rich, non-discursive, knowing. ${ }^{10}$ Bernstein's reading thereby expresses Hegel's rejection of content-rich, sensuous knowing.

\section{Systematic Considerations of Beginning and Sensuous-Certainty}

"The beginning," Hegel writes in The Science of Logic, "must then be absolute or, what means the same here, must be an abstract beginning; and so there is nothing that it may presuppose, must not be mediated by anything or have a ground, ought to be rather itself the ground of the entire science."11 The mediate will return, as Hegel says "there is nothing in heaven or nature or spirit or anywhere else that does not contain just as much immediacy as mediation."12 Beginning with the immediate, being as such or pure being, thereby engenders the organic development of the system and so overcomes the dogmatic metaphysics of the past. Sensuous being is recuperated as an expression of absolute essence, and sensuous consciousness (i.e., spirit) is an abstraction of this; that is, it is one-sided. ${ }^{13}$ Thus, the beginning is not irrelevant; a point which Hegel makes more generally in his Logic: "The beginning of philosophy is the ever-present and self-preserving foundation of all subsequent developments, remaining everywhere immanent in its further determinations."14 If we are to investigate sensuous-certainty, then an analysis will be twofold, i.e., have both a moment of mediated and immediate sense.

The two initial conceptions provided by Hyppolite and Bernstein can be understood as the expression of this twofold nature. On the one hand, Hyppolite would have us ultimately mediate the meaning through absolute knowing and, in part, the sensuous soul; on the other hand, Bernstein takes sensuous-certainty primarily in its immediate context. We thereby need to look back from the end, and so the question takes on a final determination: what is the meaning of sensuous-certainty as disavowal of the mediate? Hegel characterizes it generally: "immediate knowing has the truth for its content only taken in isolation, to the exclusion of mediation." 15 Structurally, it would deny limits, and in this way appears as a parody of the true infinity of thinking in the manner of there being nothing

9. G.W.F. Hegel, The Phenomenology of Spirit, trans. Terry P. Pinkard, (Cambridge: Cambridge University Press, 2018), \$27. Hereafter cited as PS.

10. Brady Bowman, "Spinozist Pantheism and the Truth of 'Sense Certainty': What the Eleusinian Mysteries Tell Us about Hegel's Phenomenology." Journal of the History of Philosophy, vol. 50, no. 1 (January 2012): 85-110, https:// doi.org/10.1353/hph.2012.0019.

11. G.W.F. Hegel, The Science of Logic, trans. and ed. George di Giovanni, 48. Hereafter cited as SL.

12. SL 46.

13. PS $₫ 760$.

14. SL 49.

15. EL $₫ 65$. 
outside of thought in such a way that there is an identity of being and thought. That is, in Hyppolite's view, summarized by Judith Butler in her book on French Hegelianism, "[T]o think the absolute is to engage both a knowledge of temporality and a temporal experience of this truth; in effect, the truth of time must be suffered to be known."16 Sensuous-certainty denies the need for this suffering in the labor of knowing. Yet, since it is overcome (sublated), immediate knowing is preserved and refigured as posited by later shapes. With a view to where we are going, a richer systematic meaning can be grasped, namely, that sensuous-certainty prepares the setting that is to become the midden heap of history to be reconciled. Since this beginning undergirds the whole development, what it does as a shape of cognition or consciousness needs to be articulated, and, in order to do so, the whole movement of immediate knowing must be grasped.

\section{Analysis of Sensuous-Certainty as a Single Movement}

In the first act, sensuous-certainty has already divided the world into the mediate and immediate, but, beyond the mere division, it disavows the mediate pole and thinks immediacy as self-sufficient, i.e., without the need for mediation. ${ }^{17}$ When we go to test consciousness, we ask it a question, we write down the answer, and our answer proves to be untrue, e.g., the now is the night, in the middle of the day ... What has happened to our truth? The now became mediated: "This selfmaintaining Now is thus not an immediate Now but a mediated Now, for it is determined as an enduring and self- maintaining Now as a result of another not existing, namely, the day or the night."18 The contradiction is expressed by the two propositions: now is the night and now is the day. From the outside, we can see that it is not the mediation that produces a contradiction, but a disavowal of mediation that produces the contradiction by which two contrary predicates emerged out of the subject. The immediate fails to mean a single thing, and so it turns out that "[immediacy] is indifferent to what is in play alongside it." 19 In short, it means nothing at all. This also occurs with this as here.

The result is that objective, sensuous intuition is universal, yet some, namely Feuerbach, say that only what we did is universal. Robert Solomon summarizes the critique by Feuerbach: "what Hegel is fallaciously doing here is attacking a certain claim about the word 'this' (and others like it)

16. Judith Butler, Subjects of Desire: Hegelian Reflections in Twentieth-Century France, (New York: Columbia University Press, 2012), 83-84.

17. The dialectic of sensuous-certainty, while a single movement, is divided into three moments, which I call the first act, second act, and the third act. Each is not a proper sublation but propels the development in exposing different sides of the contradiction.

18. PS 996.

19. PS $\uparrow 96$. 
instead of making the point he thinks he is making about the nature of experience." 20 He comes to argue that Hegel's critique falls flat because there is a contradiction between word (universal) and world (particular); however, I think that Robert B. Pippin provides a good response to the issue when he says, "The reference to language, in other words, plays an explanatory, not a justificatory, role." 21 Our questions and answers are grounded in sensuous-certainty experience, i.e., it is not alien to it in meaning. For, as Hegel maintained, "The dialectic which it has in itself will take on a form as intelligible as the 'This' itself." 22 Further, "we need only to consider [how the object] as sensuouscertainty has in it sensuous-certainty itself." 23 We are speaking on the behalf of consciousness, and so the university of sensibility is not an alien imposition.

Regarding the universality of the sensuous, Hegel says, "We thereby of course do not represent to ourselves the universal This or being as such, but we express the universal; or, in this sensuous certainty we do not at all say what we mean." 24 Neither we nor consciousness present "being as such" to ourselves, for it is not that we are taking existence and reflecting on it. What is at stake here is the question of what is given, or, as W. Clark Wolf puts it, taken in experience. ${ }^{25}$ This is so that nothing besides pure being is taken in immediacy, no matter how much content one would posit as in sensuous being. The reason for needing to speak is best expressed by Hyppolite in his book Logic and Existence, where he writes that "the sensible ... turns into sense by negating itself as sensible."26 Further, Bernstein notes that our methodology is more complex than sensuous-certainty, in the sense that it is not yet capable of engaging in sense-making proper. ${ }^{27}$ Taken in conjunction with Hyppolite, this analysis must be narrated in language for us and consciousness must develop further before it can understand its development during this shape, thereby neutralizing a Feuerbachian critique.

There is, however, a later moment in the dialectic of sensuous-certainty where a redoubled Feuerbachian critique could be made. In the third act, it is said that "we step up to [the Now] and let ourselves point." 28 Our activity would seem to be essentially different than before, for we are taking

20. Robert Solomon, In the Spirit of Hegel: A Study of G.W.F. Hegel's Phenomenology of Spirit, (New York: Oxford University Press, 1983), 68.

21. Robert B. Pippin, Hegel's Idealism the Satisfactions of Self-Consciousness, (New York: Cambridge University Press, 1989), 119.

22. PS $₫ 95$.

23. PS 994.

24. PS 997.

25. W. Clark Wolf, "The Myth of the Taken: Why Hegel Is Not a Conceptualist," International Journal of Philosophical Studies, vol. 27, no. 3 (2019): 399-421. https://doi.org/10.1080/09672559.2019.1612617.

26. Jean Hyppolite, Logic and Existence, (Albany, NY: SUNY Press, 1997), 32.

27. Bernstein, Lecture 1, Part 1, 22:48-23:52.

28. PS $₫ 105$. 
an active role. Hegel is narrating the experience of sensuous-certainty, but not in the sense of giving an empirical account of a sensuous consciousness. Sensuous-certainty is experiencing mediation, even if it would deny this if it could be asked, and all that our pointing does is show that mediation is necessarily present. Like Socrates, we guide the student to the limits and contradictions present in what is already there. In this instruction, we are not inflicting anything alien but, in a way, recollecting or bringing attention to the mediation of immediacy that is already constitutive of the experience. Herein lies the similarity between Hegel's original question and answer (what is the now) and later act of pointing. Yet before we point, we and consciousness are not bound in the experience together; this occurs when we point, which will not occur until the third act.

The second act, though brief, sees mediation rise in the immediate I. ${ }^{29}$ Hegel says, "Its truth is in the object as my object, or, in what I mean; the object is because $I$ know it." 30 Bernstein remarks that the I was there all along, which would reveal for us that the cognition of the object was the result of the reception on the part of the subject. ${ }^{31}$ In this way, I know the objects "because $I$ hold fast to them." 32 Yet, "sensuous-certainty experiences in these relationships the same dialectic as it did within the preceding relationships." 33 It thereby transpires that the $\mathrm{I}$ is also universal, i.e., objective sensuous-immediacy is not relegated to any subset, but it also occurs that receptivity is universal.

In the third act, "we thereby come to posit the whole of sensuous-certainty itself as its essence and no longer only as a moment of sensuous-certainty, as happened in both cases, in which at first the object opposed to the I and then the I itself were each supposed to be the reality of sensuouscertainty." 34 The whole of sensuous-certainty, i.e., the sum of the two parts, the I and object, is now the essence, i.e., it is no longer a container of an essential and inessential moment. This result grounds Hegel's earlier remark that "an actual sensuous-certainty is not only this pure immediacy but also an example of it." 35 This example of mediation in immediacy is not of the prior "this and not this" but the object and I with "this and not this." In the third act, therefore, instead of raising up either the self or object, both are taken up as the two co-moments of the immediate. Yet it still is caught up immediately with itself, i.e., the not here and not now, and so it "clings tenaciously in such

29. It is worth stressing the importance of this act, for, in the history of modern philosophy, the self is given a presence to itself, which Hegel begins to unmoor. Among the highest developments of this idea is that of Freud's ego, but we should see here (with hints of Kant's transcendental illusion) the capacity for a lack of immediate transparency.

30. PS $₫ 100$.

31. Bernstein, Lecture 1, Part 1, 44:00-:46:32.

32. PS $\$ 101$.

33. PS $₫ 101$.

34. PS $₫ 103$.

35. PS 92. 
sensuous-certainty to immediacy." 36 Sensuous-certainty thereby takes on the form of sleep, for sensuous-certainty "no longer wishes to step forward;" it has gone limp, succumbs to a torpid state. ${ }^{37}$ It attempts to return to sleep, to know only the infinite dream, for it has seen that to be awake is to see death. This state is, however, untenable, and now we are to point while immersed in the experience in order to demonstrate this.

With us immersed in the shape of consciousness, our thoughtless pointing enables Hegel to announce, "The Now is pointed out, this Now. Now: It has already ceased to be as it was pointed out; the 'Now that is' is an other than that pointed out, and we see that the Now is just this Now as it no longer is."38 On what has occurred, Hegel narrates:

(1) I point out the Now, and it is asserted to be the true. However, I point to it as something that has been and thus sublate the first truth, and (2) I assert the Now as the second truth, that it has been, that it is sublated. (3) However, what has been is not; I sublate that second truth, that it has been, or, its having-beensublated, and, in doing that, I negate the negation of the Now and so turn back to the first assertion, namely, that Now is. ${ }^{39}$

This movement, as Hegel says, is the "negation of the negation." 40 Yet this negation of the negation is not a reversal of act one and two; rather this negation of the negation is sublation. Sublation is negative, but that something is negated into its opposite brings with it that movement so that the negated returns, negating its negation. The pointing reveals the mutual implication, for it shows that one thing came from another and, since its result is its result, the result posits the negated original. However, there remains a gap in this analysis: why is the now I point to a has-been? Hyppolite leads us to consult the dialectic of being in The Science of Logic for an answer. In The Science of Logic, Hegel writes, "[being] is pure indeterminateness and emptiness ... it is only this pure empty intuiting itself." 41 Being, or this, passed over into nothing, or not this, because it was empty, i.e., immediate meaning really means nothing. Yet, Hegel says, "Nothing is therefore the same determination or rather absence of determination, and thus altogether the same as what pure being is." 42 Being and nothing are opposites, and so stand opposed to each other, yet the line that is supposed to separate the two does not keep them apart.

Being and nothing passed over into each other, for being is empty and nothing is realized to

36. PS 106.

37. PS $\mid 107$.

38. PS 106.

39. PS $₫ 107$.

40. SL 59.

41. PS $₫ 108$.

42. SL 59. 
be the same as being. Being = nothing, and yet are not the same; however, this is only made stable through positing being and nothing as moments of becoming as a "quiescent simplicity."43 Sensuous-certainty will produce a similar outcome: 1) the now passed away and so is not now, 2) it is not now, i.e., it is not now, and 3) that now is not now is that now has been shown to equal not now, i.e., it is now. This is all to say that the not now is just as much as the now, or the now and the not now are not different, just as being and nothing. This occurs because of the emptiness of the now, and it passes away. The equality of the now and not now is the reason for the emptiness of any intending on the part of consciousness. This also happens with the Here, that not here $=$ here, but with the chirality of three dimensions. ${ }^{44}$ The this and not this co-imply each other, and so every moment of time or space is a sublation, in the manner that implication posits co-implication. ${ }^{45}$ In regard to the shape of immediate knowing, what this means is that immediacy and mediation are essentially united. This unity is the universal ensemble of hours and minutes as continuous time and also as the continuous space of the self knowing the objective. Therefore, at this point, sensuouscertainty has been overcome, for the immediacy involves mediation. Perceptive consciousness, therefore, has supplanted sensuous-certainty by gathering and binding together the here, the now, the self, and the object, as a universal, spatiotemporal subject-object ensemble.

\section{Absolute Knowing and Sensuous-Certainty}

I asserted earlier that the sublation of sensuous-certainty prepared the space for the unfolding of the shapes of consciousness, which coalesces as the midden heap of history. From the standpoint of the end of the narration of the dialectic of sensuous-certainty, the next shape is perception, and the development continues all the way to absolute knowing. In a one-sided sense, since it was the beginning, it is merely the prior shape to other shapes. Yet, insofar as it undergirds the development, it ought be explicated from the end-from absolute knowing — and we should look back beyond a mere invocation of the explicit references to it. This richer sense can be initially grasped as the unity of the spatiotemporal subject-object ensemble, memory, and responsibility. Our venture into absolute knowing will be given in two parts: the unity of being and self, and the flux of time with the limit of space.

The identity of being and the subject is realized in the reconciliation of its moments. Hyppolite summarizes, "In [absolute knowing], the element of existence of the spirit is no longer

43. SL 59.

44. PS $₫ 108$.

45. It is a helpful comparison to think of the relation of parent and child. The parent is the anticipated condition of the child, and so the child is a being whose being involves the parent. The parent makes the child a child, and the parent is also only who they are by there being a child. 
the Dasein of consciousness, but the concept, universal self-consciousness. Spirit now reflects itself into itself in this element; it becomes the thought of itself, or logos." 46 The key idea for us is that substance has become subject, for it is that the originally posited shape in being as alienated returns to the self in its development and comes to know what has occurred.

Hyppolite says, later on, "By recollecting the entire previous experience, we should rediscover these successive alienations, which not only prove that being has been resolved into self, but that self has posed itself in being." ${ }^{47}$ Alternatively, as Jon Stewart explicates, "It realizes that the object sphere is not independent and autonomous but instead is necessarily connected with the subject and the forms of thought." 48 Being (or the objective) and the self (or the I or the subjective) are thereby understood as moments of spirit, in such a way they are two co-instantaneous moments which are identical by being of the same movement of spirit. We had begun this paper with these two attempting to be equal, and only now do we know it - the equality of truth and certainty.

The final step in absolute knowing is a reconciliation of the orginary sundering that consciousness discovered in evaporation of the night by the day through the overcoming of representational thinking by conceptual thinking. This is, however, not to say that there is no longer a present or past or future in the sense that the being of past and future are one with the being of the present. Rather, Hegel says, "Time is the concept itself that is there and is represented to consciousness as an empty intuition." 49 As Stewart summarizes:

The Absolute [Concept] ... is a conceptual movement that transcends time: 'Spirit necessarily appears in time, and it appears in time just so long as it has not grasped its pure [Concept], i.e. has not annulled time.' Now, at the end of the dialectic, consciousness 'sets aside its time-form.' Absolute knowing is an understanding not of any particular historical development, but of the necessary categorical movements hidden in history and religion, which is timeless. ${ }^{50}$

Hyppolite expresses an unease around this matter, for, according to him, the unity of the temporal and atemporal is the primary question of the Phenomenology that, at the same time, lacks a clear solution. ${ }^{51} \mathrm{He}$ understands it as a unity of knowledge and action, such that "in the element of the concept, this absolute knowledge appears as the very action of the subject that thinks it ... Thus infinite reason knows itself in human self-consciousness and is infinite only in this finite knowledge

46. Hyppolite, Genesis and Structure, 581.

47. Hyppolite, Genesis and Structure, 593.

48. Jon Stewart, The Unity of Hegel's Phenomenology of Spirit: A Systematic Interpretation. (Evanston: Northwestern University Press, 2000), 461.

49. PS $₫ 806$.

50. Stewart, The Unity of Hegel's Phenomenology of Spirit, 462.

51. Hyppolite, Genesis and Structure, 596. 
of itself." 52 In a similar way, Bernstein understands the annulling of time as the move from history to historicity, wherein time is "who we are in our continual movement of determination as ... a community of the living and the dead." 53 This reconciliation of finitude, then, completes the unity of spirit and space. As Hegel says,

Knowing is acquainted not only with itself, but also with the negative of itself, or its limit. To know its limit means to know that it is to sacrifice itself. This sacrifice is the relinquishing in which spirit exhibits its coming-to-be spirit in the form of a free contingent event, and it intuits outside of itself its pure self as time and likewise intuits its being as space. ${ }^{54}$

Time as the reconciliation of the living and the dead, i.e., the present and the past, is understood as the knowing and doing of spirit that places its future as also within it. The space which is known as its activity has the limit as its horizon, i.e., the horizon is its historical horizon. The not Now and the not Here are conceptually unified with the Now and Here as a unity with difference, in what Bernstein calls the overcoming of Kantian time, and is the production of subjectivity that thereby facilitates the transition of substance to subject. ${ }^{55}$

If we turn back to sensuous-certainty, we see that this shape produced the spatiotemporal subject-object ensemble, which, in absolute knowing, is taken up as the ground of the activity of spirit. This activity was not so until we created spirit, as Hyppolite puts it. 56 It was this abstract activity that through the dialectical development became aware of what it was an abstraction of, i.e., consciousness came to understand how its first shape was posited by its final shape. However, it, to speak metaphorically, brought together the raw materials to be developed and so stays with the development of consciousness as to hold these, the aforementioned ensemble, through the narrative. This is the bulk of the meaning of sensuous-certainty, but there are two other activities which go along with consciousness in the development, namely responsibility and memory.

The I, the object, time, and space occupy most of Hegel's time on sensuous-certainty, but in his reflection of what has occurred, he reveals a possibility of repetition within sensuous-certainty:

It is clear both that the dialectic of sensuous-certainty is nothing but the simple history of its movement (that is, its experience) and that sensuous-certainty itself is nothing but just this history. For that reason, natural consciousness also proceeds to this result, what is the true in sensuous-certainty, to keep pressing ever forward. It learns from experience about it, but then it likewise forgets it again, and then it starts

52. Hyppolite, Genesis and Structure, 599.

53. Bernstein, Lecture 30, 39:46-40:08.

54. PS $₫ 807$.

55. Bernstein, Lecture 30, Part 2, 39:20-39:25.

56. Hyppolite, Genesis and Structure, 598. 
the whole movement all over again right from the beginning. ${ }^{57}$

Randall E. Auxier points out the ambiguity inherent in this statement, namely that it is not clear if the initiates, in regard to the practical matters, are relearning or learning for the first time. ${ }^{8}$ This would divide the matter of memory into two concerns for us in regard to the consciousness which has overcome sensuous-certainty. Consciousness must remember the experience, and, on the other, must take responsibility for said experience. The essence of its experience was in the third act, and it was here where sublation was first experienced as sublation. The pointing was a primal expression of responsibility and memory that enabled the recognition of sublation, for it was only in the capacity to point and to actually point that consciousness experienced what it did. Forgetting, therefore, is a returning to the beginning, i.e., a return to pure being, but we can understand it also as a forgetting of sublation, or the united negativity of being. Thus, at the heart of the dialectic of sensuous-certainty, there is an orginary act of binding together of the parts that participated out of the sensuous soul, and it is only through memory and responsibility that the negative unity can be known.

\section{Conclusion}

Looking back on the whole of what has been examined in this, from initial conceptions to linking absolute knowing and sensuous-certainty, the meaning of sensuous-certainty as the beginning of Hegel's Phenomenology of Spirit has been explicated. Sensuous-certainty is essentially a disavowal of mediation, which, in the affirmation of mediation in its sublation, results in a drawing forth of and holding onto its results. The sublation is an affirmation, in the sense of remembering and holding true to the memory of what was disavowed, i.e., an affirmation of the spatiotemporal subject-object ensemble, which is reconciled in the creation of spirit as the theater of its activity. The abdication of this results in the necessary repetition of the dialectic of sensuous-certainty, and so this responsibility, and capacity to remember, is needed to hold true to the result of the experience it has undergone. This holding onto negativity, though consciousness does not immediately understand, is what it means to begin with sensuous- certainty.

57. PS $₫ 109$.

58. Randall E. Auxier, "The Return of the Initiate: Hegel on Bread and Wine." Owl of Minerva, vol. 22, no. 2 (1991): 195, https://doi.org/10.5840/owl199122220. 